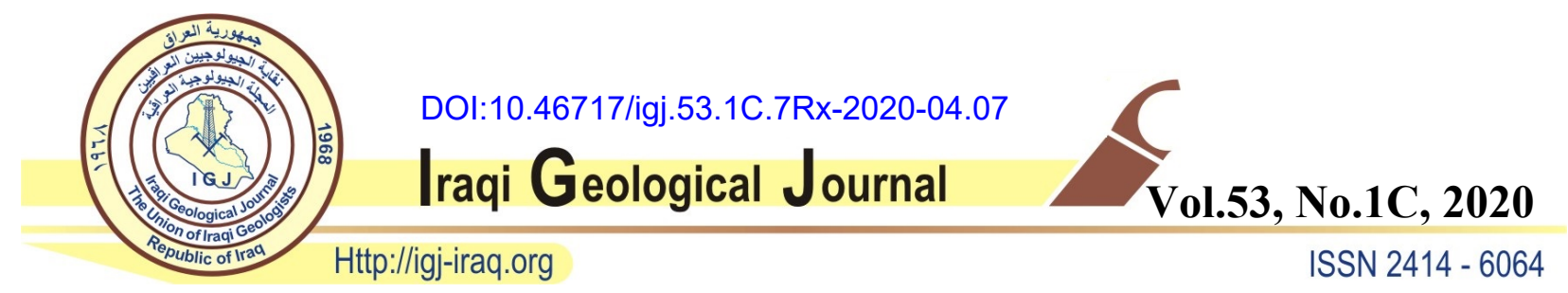

\title{
USING INSAR IMAGES (SENTINEL 1A AND B ASCENDING) TO SHOW THE SURFACE DEFORMATION OF HALABJA EARTHQUAKE 7.3 MW, 2017 IN DIYALA AREA
}

\author{
${ }^{1}$ Talal Hasan Kadhim *and ${ }^{2}$ Manal Sh. Al-Kubaisi \\ ${ }^{1}$ Iraq Geological Survey, Baghdad, Iraq \\ ${ }^{2}$ Department of Geology, College of Science, University of Baghdad \\ "E-mail: talalkazem@yahoo.com
}

Received: 7 November 2019; accepted: 29 December 2019

\begin{abstract}
The study area is affected by a high magnitude earthquake event at magnitude approximately $7.3 \mathrm{Mw}$ on November 12, 2017. This earthquake is covered by significant surface displacement. Sentinel-1 InSAR Interferogram was used to measure and analyze this displacement during 6 days and 24 days' intervals on November 11-17, 2017 and October 30November 23, 2017 before and after the occurrence of the earthquake, respectively. Derbandekhan Dam, Bamo Mountain and Diyala River are examined as a reference for the displacement of the InSAR relative measurements between the two periods of InSAR. In the Derbendekhan Dam, the area is recorded horizontal deformation toward SE direction, Bamo Mountain is recorded horizontal deformation toward SE direction and Diyala River area is recorded horizontal deformation toward SE and NW directions. While the Derbendekhan Dam area is recorded subsidence deformation, Bamo Mountain is recorded uplifted deformation and Diyala River area is recorded uplifted and subsidence deformation. Finally, the results check with geodetic observation of Derbendekhan Dam that are close to them.
\end{abstract}

Keywords: Sentinel-1; Interferogram; Diyala River area; Deformation; Derbandekhan Dam; Bamo Mountain

\section{INTRODUCTION}

The synthetic aperture radar interferometry technology (InSAR) is one of the powerful tools to measure deformation on the earth's surface. The Sentinel-1(A/B) satellite data provide synthetic aperture radar (SAR) data or images for studying surface deformation all over the world (Strozzi 
et al., 2018). Sentinel-1A satellite launched on April 3, 2014, which that provides radar image data with a range of between 5 to $22 \mathrm{~m}$, depending on the different products (User Guide of Sentinel1). The Sentinel-1A assemblage provides multiple SAR images acquisition by different dates, the Terrain Observation by progressive Scan (TOPS) and Wide of Interferogram Swath (IWS) style supporting wide area InSAR applications. The distances of the sampling ground of Sentinel-1A are $2.3 \mathrm{~m}$ in range order and $13.6 \mathrm{~m}$ directions of azimuth, respectively (Zuo, Qu, Shan, Zhang, and Song, 2016).

A destructive earthquake occurred on November 12, 2017, south of Halabjah city, near Iraq-Iran border. This earthquake locates in the N-W Zagros Thrust-Fold Belt (ZTB-ZFB); (Fig. 1), while the Zagros Mountains are uplifting since the Late Eocene as a result of the collision between the Arabian and Eurasian plates (Mouthereau et al., 2012). The Arabian plate moves towards the north-east anticlockwise direction at a rate of approximately (24-29 mm/year) towards Eurasia plate (Sella, Dixon, and Mao, 2002), A result of this collision is the convergent plates (i.e., Eurasia and Arabia plates), and the Zagros Mountains were formed. The studied area is located in many tectonic zones which are Central Iran, Sandanj-Sirjan, Zagros Suture, Balambo-Tanjero Imbricated, High Folded and Low Folded zones. Geologically, The Diyala River Basin (DRB) are different in their age and geological composition. The age of the DRB formations ranging in age from Triassic up to Pleistocene, with different types of exposed Rocks and Quaternary Sediments (Fig. 1). (Sissakian and Fouad, 2014), (Fouad, 2015) and (Alavi, 1994). Based on solutions related to seismic focal mechanism of the earthquake mainshock from several agencies compiled by the European Mediterranean Seismological Centre (EMSC), it was shown that the earthquake resulted from oblique-thrust faulting (Fig. 1). As compared to other sectors of the Zagros ZTB-ZFB, the area surrounding the earthquake has underwent a relatively low level of earthquakes during the recent times (Feng et al., 2018) (Fig. 1). This earthquake studied by (Gunce and San, 2018), (Feng et al., 2018) and other authors. These studies will be discussed in the discussion section.

The objective of this study is to determine the horizontal and vertical displacement for the study area DRB resulted from high intensity earthquake $7.3 \mathrm{Mw}$ using Sentinel 1A image data, and the verification of the results accomplished with the Geodetic Observation of Derbandekhan dam on November 14, 2017). 


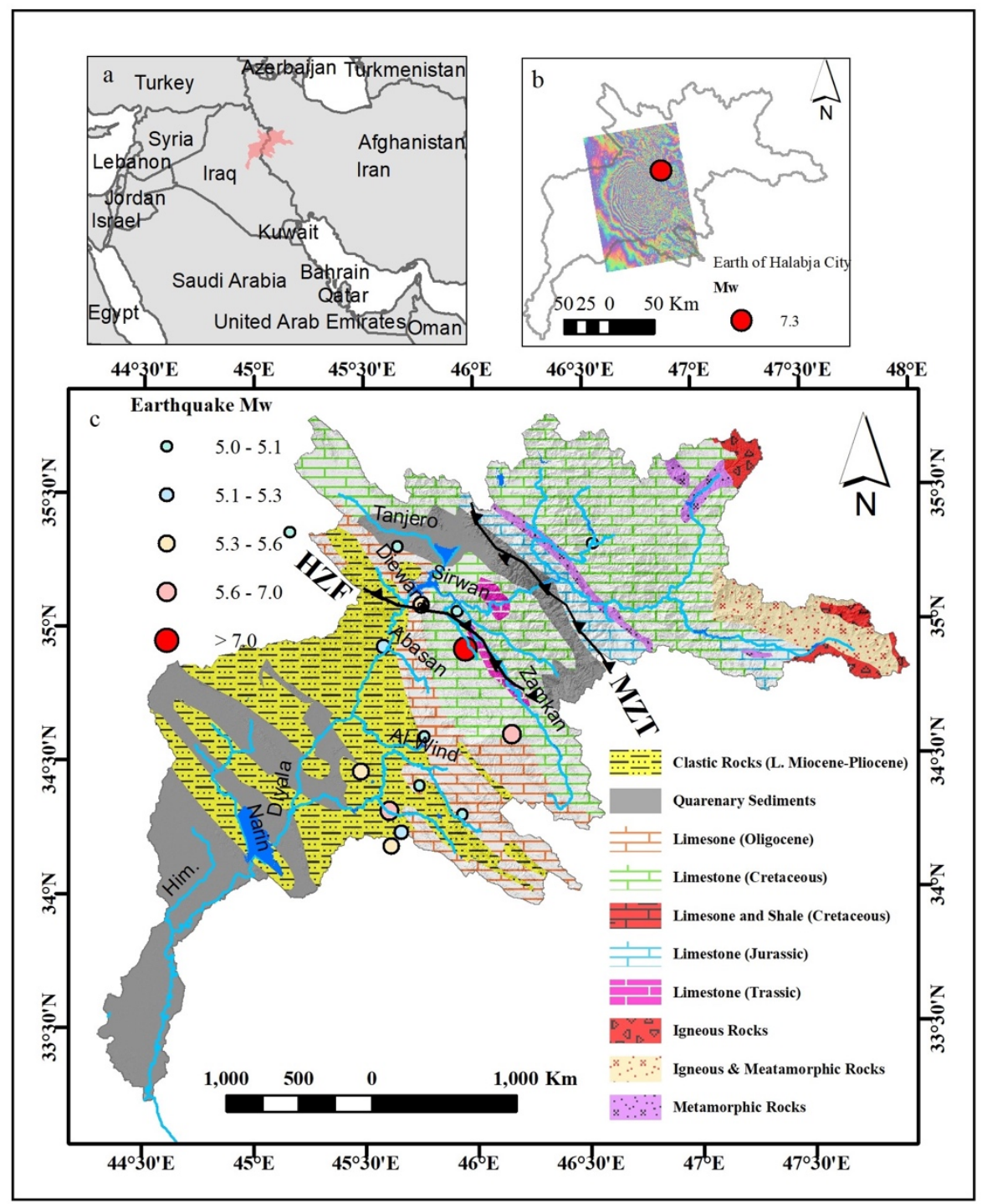

Fig. 1. DRB show MZT: main Zagros thrust, HZF: high Zagros fault modified from (Chen et al., 2018), and earthquake epicenters (USGS earthquake category)

\section{MATERIALS AND METHODS}

The four Sentinel- 1 SAR scenes are used in this study (Table 1). Stacks of two pairs from Sentinel-1 SAR images are: the first is between sentinel (1A and 1B ascending) images acquired on 11/11/2017 and 17/112019 and the second is between Sentinel (1A ascending) images acquired at October 30, 2017 and November 23, 2017 (Table 1). These two pair's images use to build two interfeograms images. The sentinel- 1 SAR image data were acquired at VV polarization over the study area. The topographic phase removal and geocoding of terrain corrected are used the ALOS Global Digital Surface Model (DSM) "ALOS World 3D-30m" 
(AW3D30) Dataset Product Format Description, Version 1.1 Digital Elevation Database 1-sec, (ALOS Global Digital Surface Model ( DSM ) "ALOS World 3D-30m” (AW3D30) Dataset Product Format Description Earth Observation Research Center ( EORC ), Japan Aerospace Exploration Agency (JAXA, 2017) (Table 2). In this study uses 6 sub-swath for IW3-VV polarization swath.

Table 1. Stack overview and optimal Sentinel-1A InSAR master and slave selection

\begin{tabular}{|l|c|c|c|c|c|c|c|}
\hline Satellite & Date/Flight dirction & Master/slave & Track & Orbit & Berp. & Btemp & M.coherence \\
\hline Sentinel 1A & $11 / 11 / 2017$ Ascending & Master & 72 & 19044 & 0 & 0 & 1 \\
\cline { 2 - 8 } Sentinel 1B & $17 / 11 / 2017$ Ascending & Slave & 72 & 19219 & 60 & -6 & 0.97 \\
\hline Sentinel 1A & $30 / 10 / 2017$ Ascending & master & 72 & 19044 & 0 & 0 & 1 \\
\cline { 2 - 8 } Sentinel 1A & $23 / 11 / 2017$ Ascending & Slave & 72 & 19394 & 7.22 & -24 & 0.97 \\
\hline
\end{tabular}

Table 2. Characteristics of the SRTM data used in this study

\begin{tabular}{|c|c|c|c|c|c|}
\hline Dataset & Imaging system & Wavelength & Pixel size & Horizontal accuracy & Vertical accuracy \\
\hline ALOS AW3D & Optical & $0.52-0.77 \mu \mathrm{m}$ & $30 \mathrm{~m}$ & $5 \mathrm{~m}$ (RMSE) & $5 \mathrm{~m}$ (RMSE) \\
\hline
\end{tabular}

The Snap V.6.0, Snaphi Version 1.4.2 and ArcGIS V.10.6 are used in. The first program is used to Sentinel 1 image processing and InSAR (wrapping interferogram) image data producing, the second program is used to convert of wrapping interferogram to unwrapping interferogram for the surface displacement calculation, and the latter program is used to produce layout map.

The investigations are based on compound interferograms acquired to provide consistent series of interferogram with 12 and 24-day time intervals (Table 1), which show very good coherence conditions (Table 1). The first InSAR processing sequence includes the co-registration of the single look complex Sentinel- 1 image IW3 (Fig. 2) (Veci, 2015). The computation of interferogram in series and over every two periods (12 and 24 days) at the after of the large earthquake $7.3 \mathrm{Mw}$ with a multilooking factor of 5 pixels in slant-range and of 1 pixel in azimuth, the removal of the topographic related phase with use of the external DSM, with adaptive phase filtering (Goldstein and Werner, 1998).

Phase unwrapping using a minimum cost-flow algorithm (Goldstein and Werner, 1998). The low-pass phase filter, computation of cumulative displacement maps and time series of movement by multi baseline InSAR (Berardino, Fornaro, Lanari, and Sansosti, 2002) and terraincorrected geocoding. 


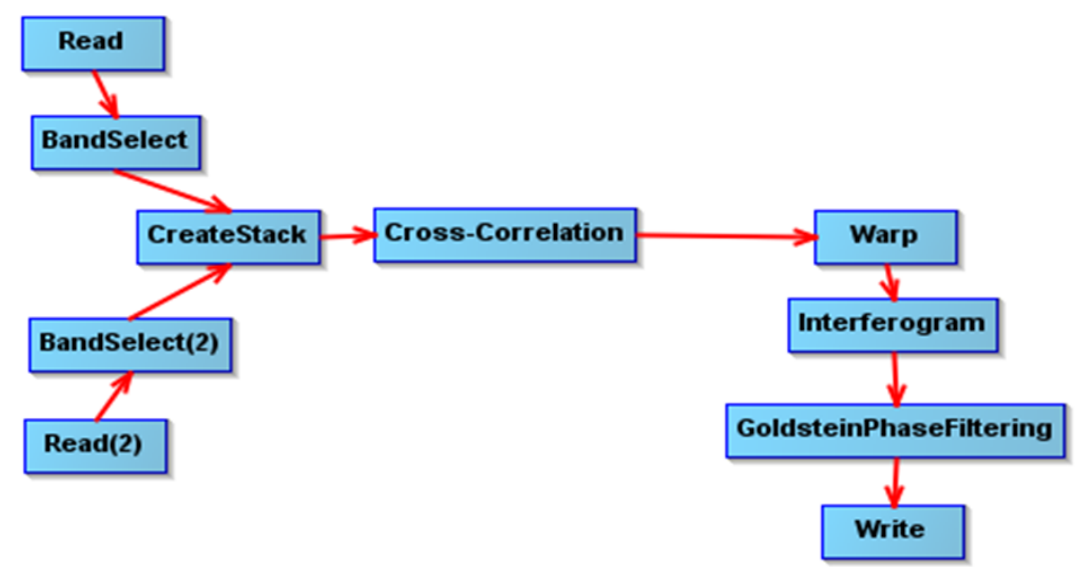

Fig. 2. Graph builder of band selected of co-registered interferogram filter (Veci, 2015)

The interferogram of phase was converted to horizontal deformation (or displacement) amount using equation (1), and the interferogram of phase was converted to vertical deformation (or displacement) amount using equation (2) (Ferretti, Monti-Guarnieri, Prati, Rocca, and Massonet, 2007).

$$
\begin{aligned}
d h & =-\frac{\lambda . \Delta \emptyset d}{4 \pi} \ldots \ldots \ldots \ldots . \ldots 1 \\
d v & =-\frac{\lambda \Delta \emptyset d}{(4 \pi * \cos (\operatorname{rad}(\text { incdent angle }))} \ldots \ldots \ldots .2
\end{aligned}
$$

The interferometry of phase is calculated before of preprocessing snaphu in Sentinel 1 radar images data in three stages. The first stage included seven steps that is illustrated in Figure (2). The second stage included three steps: Snaphu export, Snaphu import, and unwrapping Snaphu. Then, the deformation (displacement) amount is measured by equation 1, and 2 . The latter stage is geometric terrain correction by range doppler of terrain correction operator, and radiometric normalization. The range doppler of terrain correction operator (Fig. 3) with elevation, h: above the ellipsoid is imaged at position B' in SAR image, though its real position is B". The offset $\Delta_{\mathrm{r}}$ between $\mathrm{B}^{\prime}$ and $\mathrm{B} "$ : exhibits the effect of topographic distortions and radiometric normalization that depend on the approach proposed by (Veci, 2015). The interferogram, unwrapping interferogram and the displacement data have been obtained from the Sentinel-1 ascending datasets cover the study area are given in Figures $(4 \& 5)$. These results are obtained over 6 days and 24 days' periods, as specified previously. In Figure (4a), the Interferogram phase of Sentinel- 
ascending (11-19/11/2017) represented by each rainbow color cycle shows the deformation fringes with line of sight (LOS) range from -3.13 to 3.13 phase $(\pi)$ or -2.85 to $+2.85 \mathrm{~cm}$ (Fig. $4 a$ ).

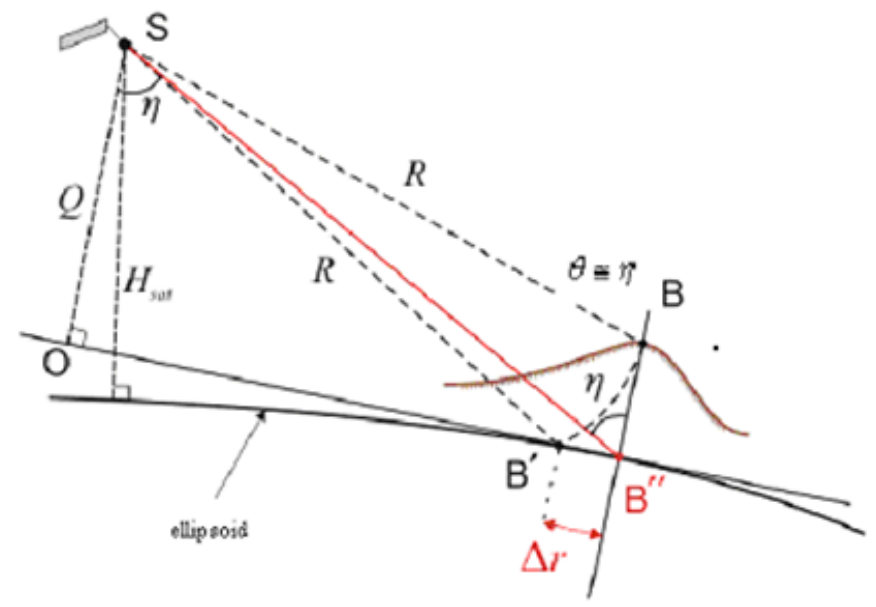

Fig. 3. The range doppler of terrain correction operator (Veci, 2015) RESULTS

These rainbow fringes can be consedred as an idea of displacement shapes. These rainbow fringes are away from each other in the low deformation area and high deformation when these rainbow fringes are close circle to each other. Also in Figure (4.a), the fault line that led to the earthquake can be clearly identified. The unwrapped Interferogram of phase image data ranges from -1971.61 to 44.32 Abs_phase (Fig. 4b). All the color fringes are unwrapped interfergram using to produce horizontal and vertical displacement image data by equation 1 and 2 and the reddish and bluish colors show relative deformations. This Figure also provides the thrust fault along the study area. All the color fringes are unwrapped interfergram using to produce of horizontal and vertical displacement image data by equation 1 and 2 in the study area. The minimum and maximum horizontal displacements were obtained as -0.19 to $0.87 \mathrm{~m}$. (Fig. 5c) and the minimum and maximum vertical displacements were obtained as -0.27 to $1.21 \mathrm{~m}$ (Fig. $5 \mathrm{~d}$ ), according to the InSAR processing. These obtained displacement amounts are directly related to the distance of the sensors. These measurements gave the differences in distance between the sensors and the terrain. Although this information is the result of relative measurements, it gives us an idea about the spatial distribution of the measurements and the relative amount of surface deformation.

In Figure (5a), the Interferogram phase of Sentinel-1 ascending (30/10-23/11/2017) represented by each rainbow color cycle shows the deformation fringes with line of sight (LOS) 
range from 3.141 to 3.141 phase $(\pi)$ or -2.85 to $+2.85 \mathrm{~cm}$ (Fig. 5a). These rainbow fringes can be idea of displacement shapes. These rainbow fringes are away from each other in the low deformation area and high deformation when these rainbow fringes are close circle to each other. Also, in Figure (5a), the fault line that led to the earthquake can be clearly identified.

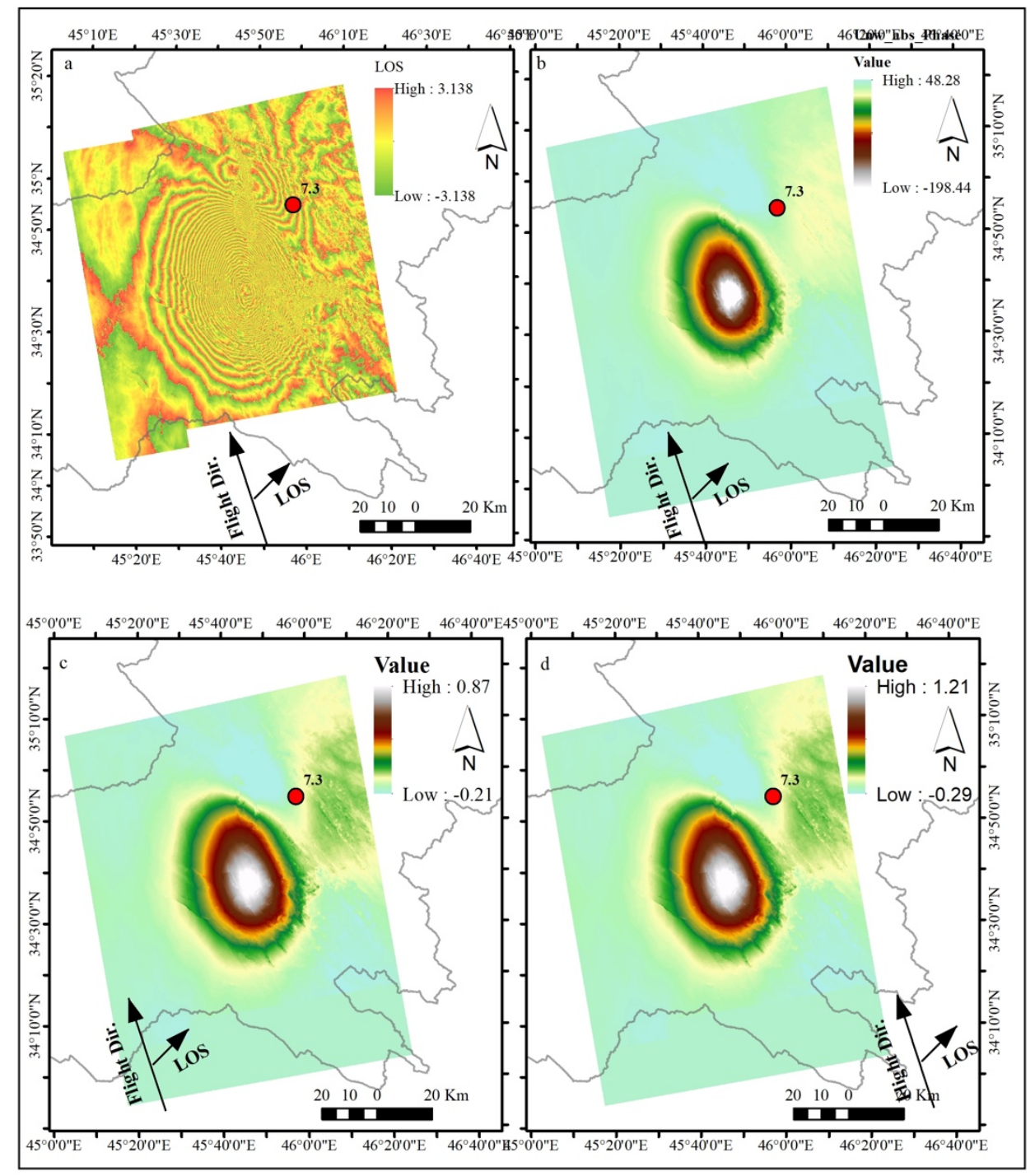

Fig. 4. a-b) Phase and unwrapped phase respectively, c-d) horizontal and vertical deformation respectively derived from Sentinel $1(11-19 / 11 / 2017)$ of the study area

The unwrapped Interferogram of phase image data ranges from -211.38 to 38.52 Abs_phase (Fig. 5b). All the color fringes are unwrapped interfergram that were used to produce horizontal and vertical displacement image data by equation 1 and 2 and the reddish and bluish colors show relative deformations. This Figure also provides the thrust fault along the study area. All the color 
fringes are unwrapped interfergram that were used to produce horizontal and vertical displacement image data by equation 1 and 2 in the study area. The minimum and maximum horizontal displacements were obtained as -0.17 to $0.93 \mathrm{~m}$. (Fig. 5c) and the minimum and maximum vertical displacements were obtained as -0.23 to $1.29 \mathrm{~m}$ (Fig. $5 \mathrm{~d}$ ), according to the InSAR process.

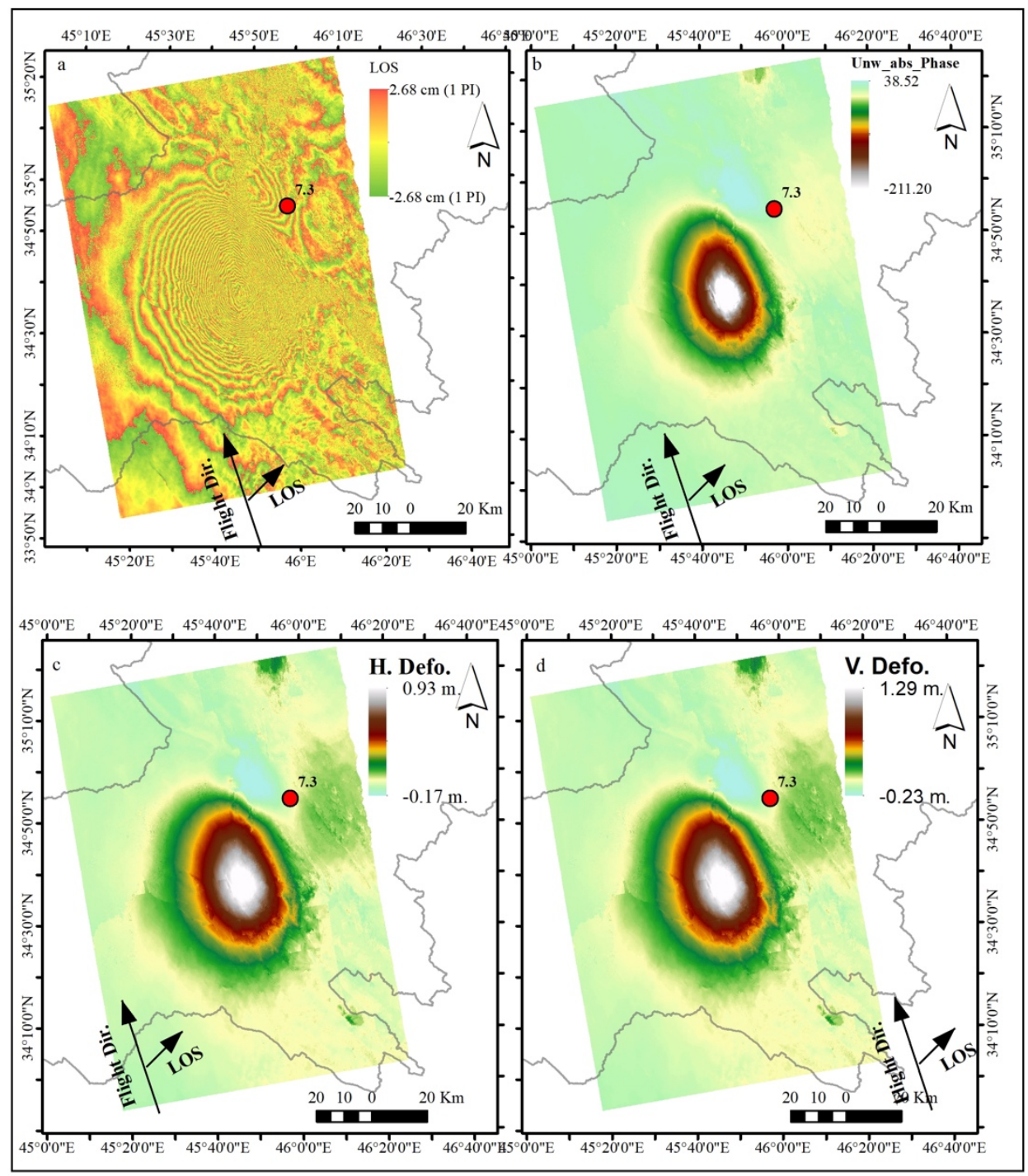

Fig. 5. a-b) Phase and unwrapped phase respectively, c-d), c) horizontal and vertical deformation respectively derived from Sentinel $1(30 / 10-23 / 11 / 2017)$ of the study area 


\section{DISCUSSION}

The surface vertical and horizontal deformation resulting from the InSAR for the period (1117/11/2017) are represented by the surface vertical deformation which display a maximum uplift of $1.21 \mathrm{~m}$ in Bamo Mountain and a subsidence zone with a maximum fullness of $0.25 \mathrm{~m}$ at halabja and Derbandikhan cities (Figs. 4\&5). The surface horizontal deformation that display a maximum of $0.87 \mathrm{~m}$ in Bamo Mountain and a subsidence zone with a maximum subsidence of $0.19 \mathrm{~m}$ at Halabja and Derbandikhan areas (Figs. 6 and 7).

The surface vertical and horizontal deformations resulting from the InSAR for the period $30 / 10 / 2017-23 / 11 / 2017$ are represented by the surface vertical deformation resulting from the InSAR with a maximum uplift of $1.28 \mathrm{~m}$ in Bamo Mountain and a subsidence zone with a maximum fullness of $0.20 \mathrm{~m}$ at halabja and Derbandikhan cities (Figs. 6\&7). The surface horizontal deformation resulting from the InSAR displays a maximum is $0.93 \mathrm{~m}$ in Bamo Mountain and a subsidence zone with a maximum fullness of $0.14 \mathrm{~m}$ at Halabja and Derbandikhan areas (Fig.s 4and 5). This provides a visualization of how the terrain of the earthland system changes and how the local and scape is changed through earthquake or seismic events in the area.

(Gunce and San, 2018) used Sentinel 1B (descending) to measure the displacement surface (horizontal) about -0.45 to $0.49 \mathrm{~m}$. this result obtained from period 12 days (7-19/11/2017). The differences in this result are logic for the following causes. The first is perpendicular baseline distance between images are used from (Gunce and San, 2018) about -15 meters (https://baseline.asf.alaska.edu/) but, the perpendicular baseline distance between images are used in this study is $-7 \mathrm{~m}$ (table 1). The second is the period between images 12 days is used (Gunce and San, 2018) and period in this study is 24 days, this period represented the center time (12 days before and after earthquake). In addition to, aftershocks occurred after the main earthquake 7.3 Mw (USGS earthquake catalog) led to increase surface deformation and Gunce and San ,2018 used large area to measure deformation, some parts of this area away from high intense of the earthquake, in this case the result must be corrected by a plane surface that is not changed by earthquakes. The latter, the area studied by Gunce and San, 2018 is extended to west towards Iranian land and the area in this study is extended to east toward Iraqi land.

(Feng et al., 2018) calculated the Bamo Mountain to be uplifted about 1 meter during the earthquake 7.3 Mw. And they did not calculate the horizontal displacement during the earthquake 7.3 Mw. Feng et al. 2018 calculated surface maximum uplifted deformation to be 
about $0.8 \mathrm{~m}$. at Bamo Mountain and they calculated the maximum subsidence zone to be about $0.4 \mathrm{~m}$. These results derived from 5 periods after earthquake occurred. In this study, Bamo Mountain uplifted about $1.21-1.28 \mathrm{~m}$ during the earthquake occurred.

(Vajedian et al., 2017) calculated the horizontal displacement to be about $1 \mathrm{~m}$. using sentinel 1 data for two periods 7-19/11/2017 descending and 11-19/11/2017of ascending. This result is close to the horizontal displacement in this study. (Al-husseinawi, Li, Clarke, and Edwards, 2018) were calculated the horizontal displacement which is about $0.17-0.5 \mathrm{~m}$. for derbandikhan dam using Sentinel 1 image for 14 periods after earthquake 7.3 Mw extend from 19/11/2017 to 7/3/2018 and the result is corresponded with Observed of Derbandekhan dam on November 14 2017), the result of (Al-husseinawi et al., 2018) is not corresponding with Observed Derbandekhan dam on November 14 2017). While, the result in this study is very closely with Observed Derbandekhan dam on November 14 2017) see Figure (6).

(Kobayashi, Morishita, Yarai, and Fujiwara, 2019) were calculated the surface deformation: the maximum vertical displacement is reaching $0.90 \mathrm{~m}$. and horizontal displacement is reaching $0.50 \mathrm{~m}$. westward using of ALOS-2 SAR (Kobayashi et al., 2019). The result of Kobayashi et al. 2019 represented by two periods, the first is ascending $(9 / 8 / 2016-14 / 11 / 2017)$ and the second is descending (4/10/2017-14/11/2017). The vertical displacement is very close to the vertical displacement in this study while the horizontal is somewhat different due to differences in periods time and wavelength images between the two studies.

(Wang, Zhang, Wang, and Liu, 2018) calculated the surface deformation from two satellites, ALOS-2 (9/8/2016 -14/11/2017 ascending and 4/10/2017 - 15/11/2017 descending) and Sentine1 A (11-23/11/2017 ascending and 7-19/11/2017 descending), Wang et al 2018 are calculated the maximum vetical deformation about $100 \mathrm{~cm}$ in ascending, $50 \mathrm{~cm}$ in descending, minimum vertical $-30 \mathrm{~cm}$ in ascending and -50 in descending images of ALOS-2 SAR ascending images. Whereas, the results in Sentinel 1 InSAR were the maximum vertical deformation about $90 \mathrm{~cm}$ in ascending, $50 \mathrm{~cm}$ in descending, minimum vertical is $-10 \mathrm{~cm}$ in ascending and $-40 \mathrm{~cm}$ in descending images. While, the horizontal deformation was reached $-50 \mathrm{~cm}$ toward west and the maximum reached $100 \mathrm{~cm}$. these results are close to the results of this study especially the results derived from Sentinel 1 (11-17/11/2017).

\section{Error Acurracy Assessment}

The first attempt to assess the uncertainty of the surface uplift-subsidence Sentinel-1A products considers past measurements of C-band over mid-latitudes areas, where a like high degree of 
modeled coherence over a multi annual period is usually observed as in 24 days over DRB area. The major validation project (Ferretti et al., 2007) an error of single measurements in C-band is a range from 6 to $7 \mathrm{~mm}$. This error is distributed to noise $(1$ to $1.2 \mathrm{~mm})$ and to atmospheric affects (4.2 to $5.5 \mathrm{~mm}$ ). The Stacking of two scenes of Sentinel-1A 24-days interferograms in a row (interferograms A-B) was performed, the results of the noise in an expected displacement error were about 1.4 to $2.8 \mathrm{~mm}(2 / \mathrm{sqrt}(2) * 1$ or $2 \mathrm{~mm}$ ) and of 5.9 to $7.7 \mathrm{~mm}$ for the atmosphere (lack of atmosphere effects in the scenes used). Altogether, the maximum expected of displacement error is approximately $0.28 \mathrm{~cm}$.

The main error sources of the InSAR quality in mid-latitudes areas are tropospheric disturbances and phase noise, but we should take into consideration the potential effects on the phase of InSAR of variables which are soil moisture (Crosetto et al., 2009), ionospheric (Gomba, Parizzi, De Zan, Eineder, and Bamler, 2015), vegetation (Zwieback and Hajnsek, 2016) and snow-cover (Guneriussen, Hogda, Johnsen, and Lauknes, 2001) conditions. The existence and systematic changes of these variables in differential interferometry measurement may lead to reduction in the accuracy of the calculated deformation. Therefore, It is so difficult to identify or characterize the impact of all these variables effect on the observed interferogram phase, because, the models to derive relative interferogram phase changes are not existing in all these variables (Strozzi et al., 2018). On the other hand, sensing the snow cover is not available in DRB at aquired Sentinell date but sensing the soil moisture, vegetation characteristics and the ionosphere condition of DRB areas at enough spatial and temporal scale is nearly impossible. Therefore, keep in mind the maps displayed at Fig.s and graphs 4 to 5 might not only represent surface displacement but also changes in soil moisture, ionosphere, and vegetation conditions. At this time, we have to choose places that are not subjected to the influence of these variables such as Derbandekhan dam bodies and exposed rock to reduce the effects of these variables.

\section{Sentinel1 InSar Results Validation}

To validate the results from Sentinel 1, a comparison is used between the two pairs interferograms results (11-19/11/2019 and 30/10-23/11/2019), where the results are a very close (Fig. 4\&5), as above mentioned. In addition to, three profile section are distributed in the study area which are AA" BB" and CC" (Fig. 6 and 7). 


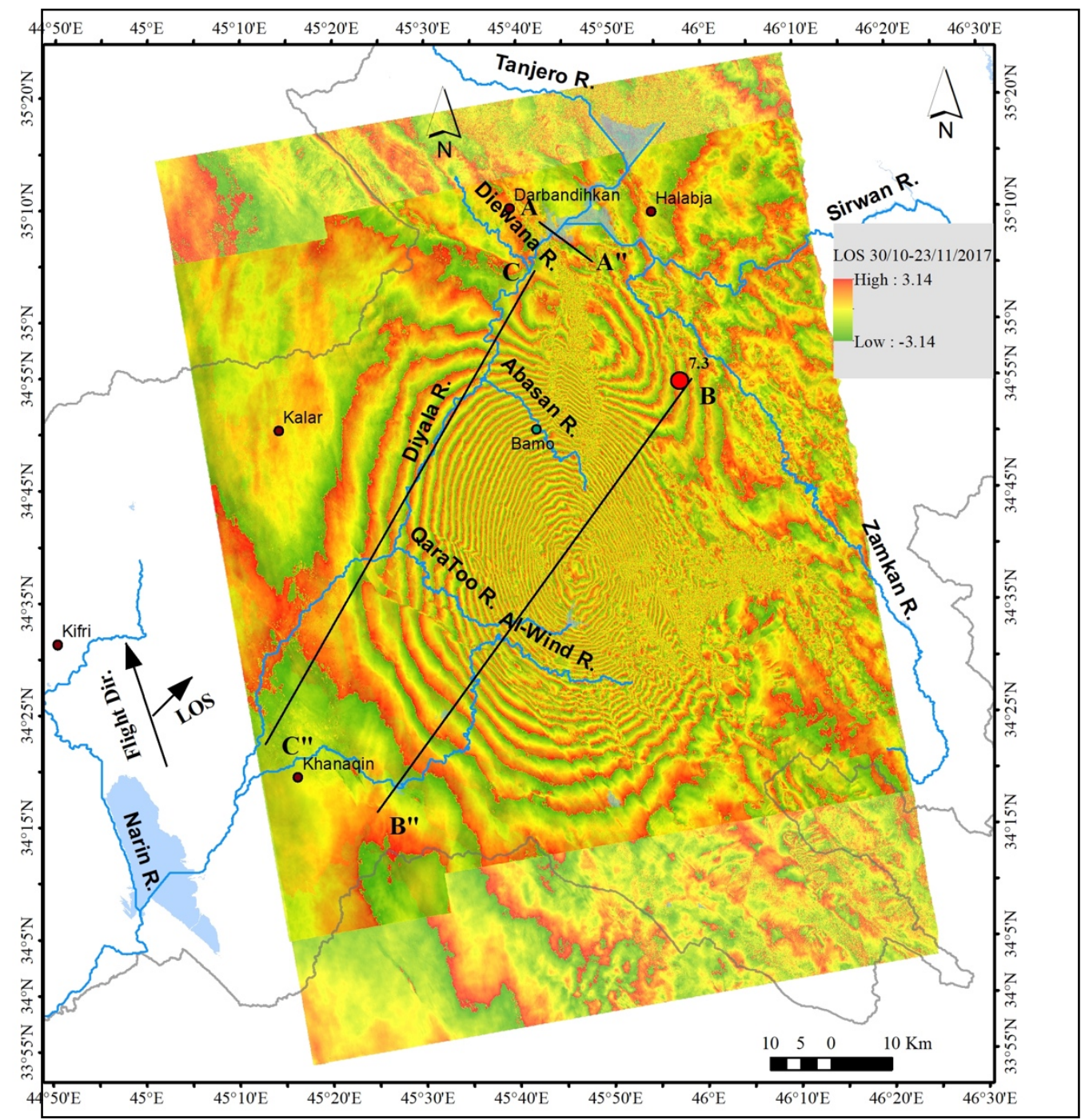

Fig. 6. Cross section profile locations in the study area (AA", BB" and CC")

In AA" section, the horizontal deformation of Derbendekhan Dam is about $1.9 \mathrm{~cm}$ to $4 \mathrm{~cm}$ at 11 $17 / 11 / 2017$ and the horizontal deformation is $2 \mathrm{~cm}$ to $5.8 \mathrm{~cm}$ at $30 / 10-23 / 11 / 2017$ and the horizontal of AA" direction is toward NE. While, the vertical deformation (subsidence) of Derbendekhan Dam is about $2.2 \mathrm{~cm}$ to $5.9 \mathrm{~cm}$ at $11-17 / 11 / 2017$ and the vertical deformation (subsidence) is $4 \mathrm{~cm}$ to $8 \mathrm{~cm}$ toward at $30 / 10-23 / 11 / 2017$.

In BB" section, the horizontal deformation of Bamo Mountain is about $86 \mathrm{~cm}$ at 11$17 / 11 / 2017$ and the horizontal deformation is $92 \mathrm{~cm}$ at 30/10-23/11/2017 and the horizontal of BB" direction is toward NE. While, the vertical deformation (uplift) of Derbendekhan Dam is about $121 \mathrm{~cm}$ at $11-17 / 11 / 2017$ and the vertical deformation (uplift) is $129 \mathrm{~cm}$ at 30/10$23 / 11 / 2017$. 


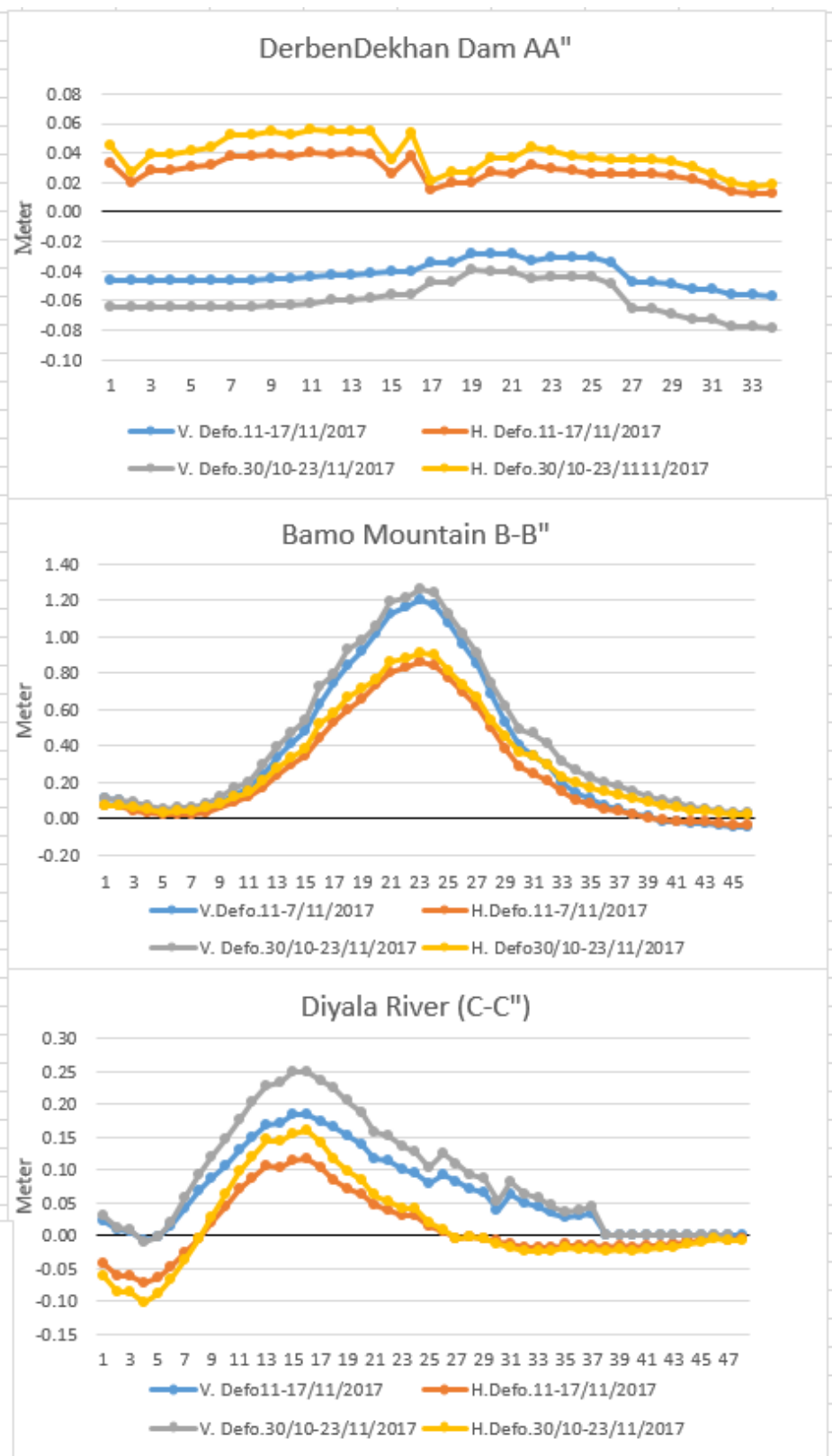

Fig. 7. Cross section profile in the study area (AA" in Derbendekhan, BB" in Bamo

\section{Mountain and CC" along on Diyala River areas}

In CC" section, the horizontal deformation directions of Diyala River are divided into three direction. The first direction is 7 and $10 \mathrm{~cm}$ at 11-17/11/2017 and 30/10-23/11/2017 respectively and toward SE and located near Derbendekhan dam. The second direction is 12 and $16 \mathrm{~cm}$ at 1117/11/2017 and 30/10-23/11/2017 respectively and toward NE and located between Abasan and QaraToo rivers. The third direction is 0 and $-2 \mathrm{~cm}$ at $11-17 / 11 / 2017$ and $30 / 10-23 / 11 / 2017$ 
respectively and toward SE located and located between QaraToo to Al-Wind Rivers. The first is uplifted from 121 to $129 \mathrm{~cm}$ at 11-17/11/2017 and 30/10-23/11/2017 respectively and located near Derbendekhan dam. The second is uplifted from 121 to $129 \mathrm{~cm}$ at 11-17/11/2017 and 30/1023/11/2017 respectively and located between Abasan and QaraToo Rivers. And the vertical deformation (uplift) is $129 \mathrm{~cm}$ at 30/10-23/11/2017. The third is low subsidence about $0.1 \mathrm{~cm}$ and located between QaraToo to Al-Wind Rivers.

These results are very close to each other, and according to (USGS Earthquake Catalog) the 27 aftershock earthquakes occurred after the main earthquake $7.3 \mathrm{Mw}$ during 12-17/11/2017 period and 40 aftershock earthquakes occurred after the main earthquake $7.3 \mathrm{Mw}$ during 12/23/11/2017 period.

There is another method used to validate results which is the comparison between ground geodetic observation stations and InSAR results (Fig. 8). In the northern part of the DR, there is the geodetic observation network on the Derbandekhan dam area, the geodetic observation carried out on November 14, 2017 and compared with the previous geodetic observation on March 17, 2017. Geodetic observation of the Derbandekhan Lake baseline is in two stations (PPC6 and PP3) and distributed on the both sides of the lake to determine the horizontal displacement that take place in baseline and many points are distributed on the body dam, left and right side of lake and (Fig. 7). Where the baseline recorded displacement in the axis (X, Y) at (PPC6) located on the location left side of the lake is $10 \mathrm{~cm}$ in direction of the southeast, and the station (PP3) on the right side of the lake has a displacement is $13 \mathrm{~cm}$ in the same direction. These results are compared with the horizontal values displacement for the sites (PPC6 and PP3) which are derived from Sentinell InSAR measurement are $7 \mathrm{~cm}$ and $9 \mathrm{~cm}$ in InSAR (1119/11/2019), and $8.8 \mathrm{~cm}$ and $10 \mathrm{~cm}$ in InSAR (30/10-23/11/2019). These differences are normally due to the long period between the two geodetic observations (9 months), and movement of plate tectonic between Arabian and Eurasian plates, which it is yearly estimated $2.69 \pm 0.09 \mathrm{~cm}$ north, $2.95 \pm 0.07 \mathrm{~cm}$ east and $-0.09 \pm 0.18 \mathrm{~cm}$ vertical (Sella et al., 2002). Whereas, the results of horizontal and vertical points (BM12, Bm13 and Bm14) on the dam body, show closely correspondent with the results derived from InSAR). 


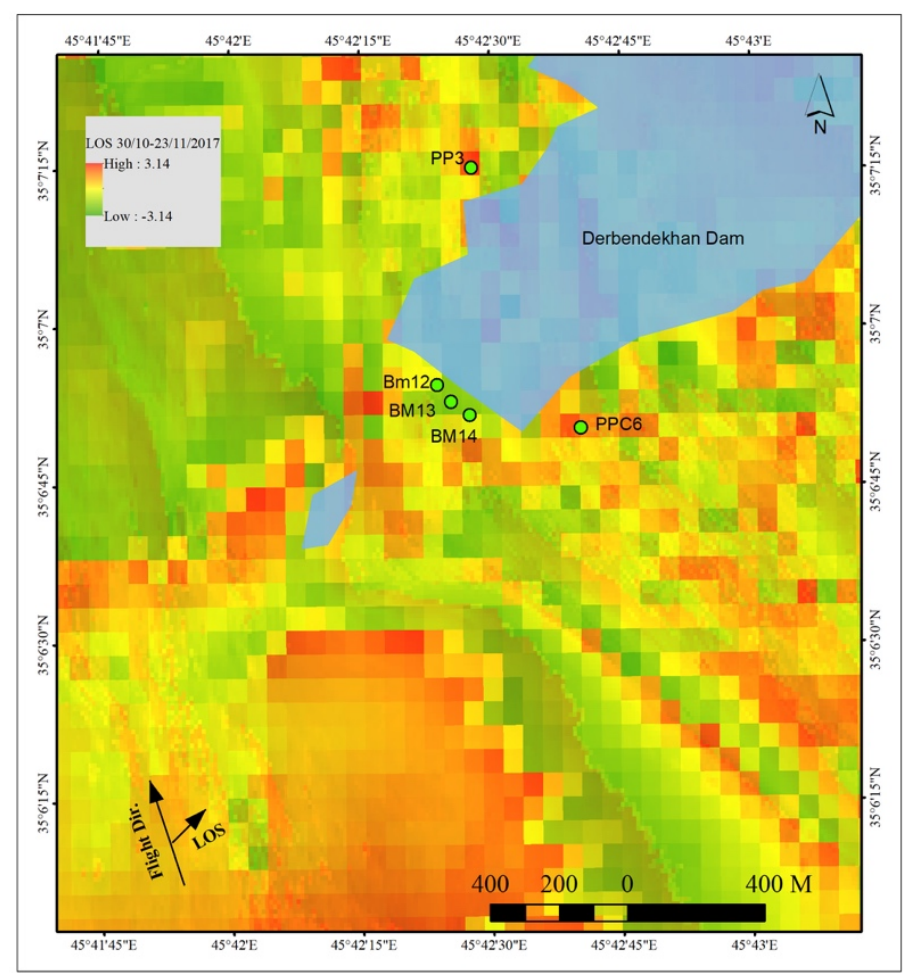

Fig. 8. PP3, PPC6, BM12, BM13 and BM14 located on Derbandekhan Area

\section{CONCLUSIONS}

The Sentinel-1 InSAR data showed helpfulness to identify the subsidence-uplift for different location landscapes and highlighted on the spatial differentiation of uplift magnitudes after large earthquake occurred. Spatial patterns observed of this process could be given to the study of the active layer plate tectonic dynamics in the different morphotectonic settings and could help to identify areas vulnerable to natural disturbances.

Generally, InSAR results propose that uplift-subsidence surface controlled by large earthquake occurred. In addition to, the movement of the Arabian plate towards Eurasian plate. Free InSAR derived uplift-subsidence products provide a general picture not only for upliftsubsidence magnitudes, also in terms of the process spatial change within landscapes that experience not only large earthquake occurrence but are subjected to plate tectonic movements. While the selected sites that aim to observe uplift-subsidence are especially suitable for a better process perception, their explanatory strength for larger spatial scales is restricted. Finally, the displacement resulting from earthquake strength does not depend only on its strength, but also depend on the quality of surface components and structures. Therefore, the displacement in the high tilted limestone bed more than from gentle tilted of clastic beds. 


\section{REFERENCES}

Al-Husseinawi, Y., Li, Z., Clarke, P., and Edwards, S., 2018. Evaluation of the Stability of the Darbandikhan Dam.

Alavi, M., 1994. Tectonics of the Zagros orogenic belt of Iran: new data and interpretations. Tectonophysics, 229(34): 211-238.

ALOS Global Digital Surface Model (DSM), 2017. “ALOS World 3D-30m ” ( AW3D30 ) Dataset Product Format Description Earth Observation Research Center ( EORC ), Japan Aerospace Exploration Agency ( JAXA ).

Berardino, P., Fornaro, G., Lanari, R., and Sansosti, E., 2002. A new algorithm for surface deformation monitoring based on small baseline differential SAR interferograms. IEEE Transactions on Geoscience and Remote Sensing, 40(11): 2375-2383.

Chen, K., Xu, W., Mai, P.M., Gao, H., Zhang, L., and Ding, X., 2018. The 2017 Mw 7.3 sarpol zahāb earthquake, Iran: A compact blind shallow-dipping thrust event in the mountain front fault basement. Tectonophysics, 747:108-114.

Crosetto, M., Monserrat, O., Bremmer, C., Hanssen, R., Capes, R., and Marsh, S., 2009. Ground motion monitoring using SAR interferometry: quality assessment. Eur. Geol, 26: 12-15.

Feng, W., Samsonov, S., Almeida, R., Yassaghi, A., Li, J., Qiu, Q., ... Zheng, W., 2018. Geodetic constraints of the 2017 Mw7. 3 sarpol zahab, Iran earthquake, and its implications on the structure and mechanics of the Northwest Zagros thrust-fold belt. Geophysical Research Letters, 45(14): 6853-6861.

Ferretti, A., Monti-Guarnieri, A., Prati, C., Rocca, F., and Massonet, D., 2007. InSAR Principles-Guidelines for SAR Interferometry Processing and Interpretation, TM-19. The Netherlands: ESA Publications.

Fouad, S. F. A., 2015. Tectonic map of Iraq, scale 1: 1000 000, 2012. Iraqi Bulletin of Geology and Mining, 11(1): $1-7$.

Geodetic Observation Team, 2017. Geodesic Observed of Derendikhan Dam on November 14 2017. Directorate of General of Dams and Reservoirs, Ministry of Water Resourses. Baghdad, Iraq.

Goldstein, R.M., and Werner, C.L., 1998. Radar interferogram filtering for geophysical applications. Geophysical Research Letters, 25(21): 4035-4038.

Gomba, G., Parizzi, A., De Zan, F., Eineder, M., and Bamler, R., 2015. Toward operational compensation of ionospheric effects in SAR interferograms: The split-spectrum method. IEEE Transactions on Geoscience and Remote Sensing, 54(3):1446-1461.

Gunce, H. B., and San, B. T., 2018. Measuring Earthquake-Induced Deformation in the South of Halabjah ( Sarpole-Zahab ) Using Sentinel-1 Data on November 12, 2017.

Guneriussen, T., Hogda, K. A., Johnsen, H., and Lauknes, I., 2001. InSAR for estimation of changes in snow water equivalent of dry snow. IEEE Transactions on Geoscience and Remote Sensing, 39(10): 2101-2108.

Kobayashi, T., Morishita, Y., Yarai, H., and Fujiwara, S., 2019. InSAR-derived Crustal Deformation and Reverse Fault Motion of the 2017 Iran-Iraq Earthquake in the Northwestern Part of the Zagros Orogenic Belt. Bulletin of the Geospatial Information Authority of Japan, 66, 2.

Sella, G.F., Dixon, T.H., and Mao, A., 2002. REVEL: A model for recent plate velocities from space geodesy. Journal of Geophysical Research: Solid Earth, 107(B4), ETG-11.

Sissakian, V.K., and Fouad, S.F., 2014. Geological Map of Sulaimaniyah Quadrangle, Scale 1: 250,000. Iraq Geological Survey Publications, Baghdad, Iraq.

Strozzi, T., Antonova, S., Günther, F., Mätzler, E., Vieira, G., Wegmüller, U., and Bartsch, A., 2018. Sentinel-1 SAR Interferometry for Surface Deformation Monitoring in Low-Land Permafrost Areas. Remote Sensing, 10(9):1360.

Vajedian, S., Motagh, M., Mousavi, Z., Motaghi, K., Fielding, E. J., Akbari, B., and Darabi, A., 2017. Coseismic Deformation Field of the Mw 7 . 312 November 2017 Sarpol-e Zahab ( Iran ) Earthquake: A Decoupling Horizon in the Northern Zagros Mountains Inferred from InSAR Observations. (November).

Veci, L., 2015. TOPS Interferometry Tutorial.

Wang, Z., Zhang, R., Wang, X., and Liu, G., 2018. Retrieving three-dimensional co-seismic deformation of the 2017 MW7. 3 Iraq earthquake by multi-sensor SAR images. Remote Sensing, 10(6): 857.

Zuo, R., Qu, C., Shan, X., Zhang, G., and Song, X., 2016. Coseismic deformation fields and a fault slip model for the 
Mw7. 8 mainshock and Mw7. 3 aftershock of the Gorkha-Nepal 2015 earthquake derived from Sentinel-1A SAR interferometry. Tectonophysics, 686: 158-169.

Zwieback, S., and Hajnsek, I., 2016. Influence of vegetation growth on the polarimetric zero-baseline DInSAR phase diversity-Implications for deformation studies. IEEE Transactions on Geoscience and Remote Sensing, 54(5): 3070-3082. 